\title{
"Work ethic" in pigeons: Reward value is directly related to the effort or time required to obtain the reward
}

\author{
TRICIA S. CLEMENT, JOANN R. FELTUS, DAREN H. KAISER, and THOMAS R. ZENTALL \\ University of Kentucky, Lexington, Kentucky
}

\begin{abstract}
Stimuli associated with less effort or with shorter delays to reinforcement are generally preferred over those associated with greater effort or longer delays to reinforcement. However, the opposite appears to be true of stimuli that follow greater effort or longer delays. In training, a simple simultaneous discrimination followed a single peck to an initial stimulus $\left(\mathrm{S}+_{\mathrm{FR} 1} \mathrm{~S}-{ }_{\mathrm{FR} 1}\right)$ and a different simple simultaneous discrimination followed 20 pecks to the initial stimulus $\left(\mathrm{S}+{ }_{\mathrm{FR} 20} \mathrm{~S}-{ }_{\mathrm{FR} 20}\right)$. On test trials, pigeons preferred $\mathrm{S}+_{\mathrm{FR} 20}$ over $\mathrm{S}+_{\mathrm{FR} 1}$ and $\mathrm{S}-_{\mathrm{FR} 20}$ over $\mathrm{S}-_{\mathrm{FR} 1}$. These data support the view that the state of the animal immediately prior to presentation of the discrimination affects the value of the reinforcement that follows it. This contrast effect is analogous to effects that when they occur in humans have been attributed to more complex cognitive and social factors.
\end{abstract}

According to traditional theories of learning (e.g., Hull, 1943; Skinner, 1938), stimuli associated with less effort and shorter delays to reinforcement should be preferred over those associated with greater effort and longer delays to reinforcement. Thus, if a pigeon learned that pecking a red stimulus would lead to a white stimulus to which a single peck was required in order to obtain food, whereas pecking a green stimulus would lead to the same white stimulus but to which 20 pecks were required in order to obtain food, it is clear that the red stimulus would be preferred over the green.

But suppose the order of the two links was reversed? What if the pigeon learned that on some trials a single peck to a white stimulus led to presentation of a red stimulus that was followed by food, and that on other trials 20 pecks to the white stimulus were required, leading to presentation of a green stimulus that was followed by food? Assume that red and green were associated (in the forward direction) with equal effort and equal delay of reinforcement; according to traditional learning theories, no preference should be expected for red or green.

However, there are other hypotheses. If the contiguity between pecks to the white stimulus and presentation of the red and green hues plays a role (e.g., Guthrie, 1935) or if the pigeon can develop a backward association between the hues and the preceding response (e.g., Spetch,

This research was supported by National Science Foundation Grant BNS-9019080 and National Institute of Mental Health Grant MH45979. Correspondence concerning this article should be sent to $T$. $R$. Zentall, Department of Psychology, University of Kentucky, Lexington, KY 40506-0044 (e-mail: zentall@pop.uky.edu).
Wilkie, \& Pinel, 1981), then one might predict that the pigeon would have a preference for the red stimulus that was presented following less effort over the green stimulus that was presented following more effort.

Alternatively, one could take the position that differential responding to the white stimulus (FR20 or FR1) might provide a context in which the hues occurred (e.g., Balsam, 1985) or that those responses set the occasion for the occurrence of the hues (e.g., Ross \& Holland, 1981). If the differential responding creates an expectancy for the stimuli that follow, preference might be determined by the FR that preceded the choice (i.e., if the choice was preceded by an FRI, the red stimulus would be preferred, but if the choice was preceded by an FR20, the green stimulus would be preferred).

Finally, one might view the time or effort associated with responding to the white stimulus as a baseline against which to assess the relative value of the hues. According to this view, the value of the hues (as a signal for food) would be judged by the pigeon relative to its state immediately prior to presentation of the hue (see Lawrence \& Festinger, 1962). Because the 20-peck requirement that precedes the green stimulus can be thought of as more aversive than the single peck that precedes the red stimulus, the onset of the green stimulus may have greater relative value than the onset of the red. According to this analysis, the phenomenon would not be unlike behavioral contrast (e.g., Reynolds, 1961). Reynolds found that when pigeons learned to peck at either of two stimuli presented successively under free-operant conditions and responding to one of the stimuli was extinguished, there was an increase in the rate of responding to the other stimulus. 

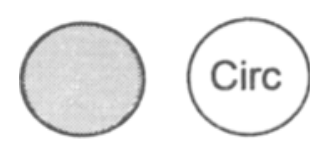

FR1

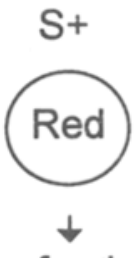

food
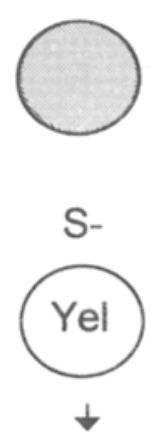

no food
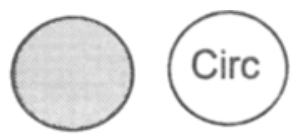

FR20

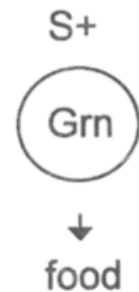

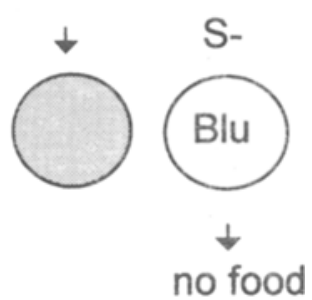

no food

Figure 1. Training trials. Each of the trial types ( $S+$ and $S$ - following FR1 to the circle stimulus and $S+$ and $S$ - following FR20 to the circle stimulus) was presented on half of the trials in each training session. Hues were counterbalanced over pigeons such that each hue served equally often as the $S+$ and the $S-$ following the FR1 and the FR20.

In a preliminary experiment in which this differentialeffort procedure was used, we did not find evidence for any systematic preference for either the hue that followed the single peck or the hue that followed the 20 pecks. We hypothesized, however, that the shift from single-stimulus presentations on training trials to two-alternative choice presentations on test trials might have obscured evidence of a preference. Specifically, in training, the pigeons might have learned to peck whatever stimulus appeared following the offset of the white stimulus. On test trials, however, they were given a choice. Pigeons in the preliminary experiment may not have learned to look for two stimuli, compare them, and choose between them.

In the present experiment, to make the procedure used in training more similar to that used in testing, we trained the pigeons on two simultaneous discriminations $(\mathrm{S}+\mathrm{S}-)$, one that followed a single peck to a white circle $\left(\mathrm{S}+_{\mathrm{FR}}\right.$ I $\left.\mathrm{S}-{ }_{F R 1}\right)$ and one that followed 20 pecks to a white circle $\left(\mathrm{S}+{ }_{F_{R} 20} \mathrm{~S}-{ }_{F R 20}\right.$; see Figure 1). A schematic of the procedure we used in training is presented in Figure 1. In this way, all trials in training and testing involved a choice of stimuli. Furthermore, by following each of the two circle-stimulus response requirements with both an $\mathrm{S}^{+}$ and an $\mathrm{S}-$, we could test the pigeons with not only the positive stimulus pair, $\mathrm{S}+_{F R 1}$ versus $\mathrm{S}+{ }_{F R 20}$, but also the negative stimulus pair, $S-{ }_{F R 1}$ versus $S-{ }_{F R 20}$. Examination of preference between the two $\mathrm{S}$ - stimuli would be informative because it is not obvious what the relationship should be between the positive and the negative stimuli in the simultaneous discriminations. On the one hand, whatever might cause one $\mathrm{S}+$ to be preferred over the other could generalize to the $S-$ presented at the same time. On the other hand, it is possible that the greater contrast between the $\mathrm{S}-$ and the preferred $\mathrm{S}+$ would instead lead to the relative avoidance of the Sstimulus that accompanied it in training.
In the preliminary experiment described, no white circle preceded the choice trials. Thus, it was possible that the absence of an initial stimulus on those test trials removed the context required for subjects to demonstrate stimulus preferences. Therefore, in the present experiment, three kinds of trial initiation preceded each of the test pairs (the two $\mathrm{S}+$ stimuli and the two $\mathrm{S}-$ stimuli). On two thirds of the test trials with each test pair, a circle was presented at the start of the trial, and on half of those trials, a single peck was required prior to presentation of the test pair (the $\mathrm{S}{ }_{\mathrm{FR} 1} \mathrm{~S}-{ }_{\mathrm{FRI}}$ context), whereas on the remaining half of the trials, 20 pecks were required (the $\mathrm{S}+{ }_{\mathrm{FR} 20} \mathrm{~S}-{ }_{\mathrm{FR} 20}$ context). On the remaining trials with each test pair, no circle was presented prior to the test (as in the preliminary experiment). A schematic of the procedure used in testing is presented in Figure 2.

\section{METHOD}

\section{Subjects}

The subjects were 8 experienced 5- to 8-year-old White Carneaux pigeons of both sexes obtained from the Palmetto Pigeon Plant (Sumter, NC). The pigeons had served earlier in a matching-tosample experiment involving yellow samples and red and green comparisons. The pigeons were individually housed in vented sheet metal and Plexiglas cages located in a colony room on a 12:12-h light:dark cycle. The pigeons, which were maintained at $80 \%-85 \%$ of their free-feeding weights throughout the experiment, had free access to water and grit in their home cages.

\section{Apparatus}

The experiment was conducted in a standard test chamber (BRS/ LVE, Laurel, MD) that measured $33 \mathrm{~cm}$ high, $35 \mathrm{~cm}$ from response panel to back wall, and $31 \mathrm{~cm}$ across the response panel. The response panel contained three horizontally aligned rectangular response keys $(3.0 \mathrm{~cm}$ wide, $2.5 \mathrm{~cm}$ high, and $0.8 \mathrm{~cm}$ apart). An in-line projector (Industrial Electronics Engineering, Model 10, Van Nuys, $\mathrm{CA}$ ) that was mounted behind each response key could illuminate the center key with a white circle (annulus) on a black background (C) and each of the side keys with red $(R)$, green $(G)$, yellow $(Y)$, and 


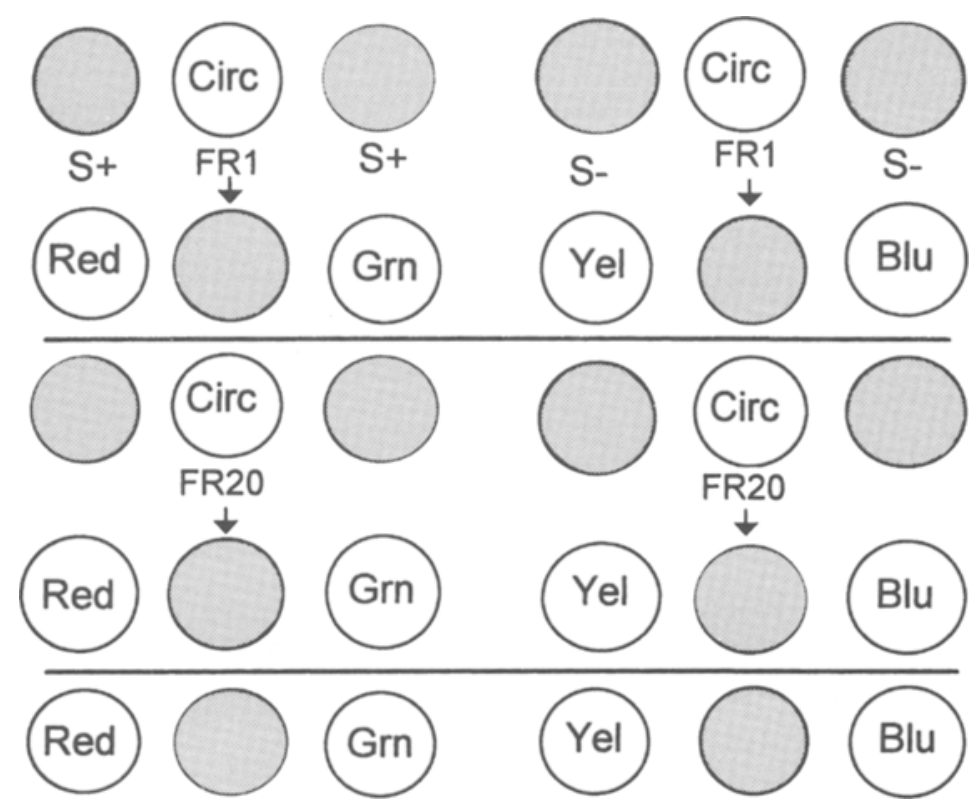

Figure 2. Test trials. The six trial types presented on test trials. Half of the test trials involved the two $S+$ stimuli from training $\left(S+{ }_{F R 1}\right.$ and $S+{ }_{F R 20}$, left side of figure) and the remaining test trials involved the two $S$ - stimuli from training (S- ${ }_{F R 1}$ and $S-{ }_{F R 20}$, right side of figure). On an equal number of the trials involving each of the trial types a single peck was required to present the test stimuli (top of figure), 20 pecks were required to present the test stimuli, or there was no prior stimulus (the trial began with the onset of the test stimuli, bottom of figure).

blue (B) hues. The pigeons' access to presentations of mixed grain (Purina Pro Grains) was permitted through a horizontally centered aperture $(5.2 \times 5.8 \mathrm{~cm})$. Reinforcement consisted of raising the illuminated feeder for $1.5 \mathrm{sec}$. A houselight mounted in the center of the ceiling provided general chamber illumination during the intertrial interval (ITI). Extraneous sounds were masked by white noise presented through a speaker mounted on the back of the response panel and by the sound of an exhaust fan mounted on the outside of the chamber. All of the events in the chamber were controlled by a microcomputer located in an adjacent room.

\section{Procedure}

Training. All of the pigeons were pretrained to peck $\mathrm{C}$ on the center key; then the response requirement was increased gradually to 20 pecks (fixed ratio, FR20). Training was started on the following day. During training, each trial began with the offset of the houselight and the illumination of $\mathrm{C}$ on the center key. On half of the trials, following one peck (FRI) $\mathrm{C}$ was terminated and two hues were presented as discriminative stimuli $\left(\mathrm{S}+_{\mathrm{FR} 1}\right.$ and $\left.\mathrm{S}-{ }_{\mathrm{FR} 1}\right)$, one appearing on each side key. On the remaining trials, following 20 pecks (FR20) C was terminated and two different hues were presented ( $S+_{F R 20}$ and $\left.S-_{F R 20}\right)$, one appearing on each side key. On all trials, a single peck to either side key turned off the other side key and initiated a 6-sec duration (during which pecks were counted). If the $\mathbf{S}+$ was pecked first, reinforcement and the ITI were initiated at the end of the 6-sec duration. If the S- was pecked first, the ITI alone was initiated at the end of the 6-sec duration. The pigeons were assigned to four subgroups ( $n=2$ each) with color counterbalanced, such that each of the four hues appeared equally often as $\mathrm{S}+_{\mathrm{FR} 1}, \mathrm{~S}-{ }_{\mathrm{FR} 1}, \mathrm{~S}+_{\mathrm{FR} 20}$, and $\mathrm{S}-{ }_{\mathrm{FRI}}$. However, to reduce the likelihood that stimulus generalization between similar hues might render the test stimuli less discriminable, the discriminations used in training involved hues that were judged to be the most difficult to discriminate (i.e., $\mathrm{R}$ vs. $\mathrm{Y}$ and $\mathrm{G}$ vs. B). Each session consisted of 96 trials, 48 involving each discrimination. In each discrimination, over trials the location of the $\mathrm{S}+$ (left or right) was counterbalanced. All pigeons were trained to a criterion of $90 \%$ correct on both discriminations $\left(S+_{F R 1} S-{ }_{F R I}\right.$ and $\left.S+{ }_{F R 20} S-{ }_{F R 20}\right)$ for one session. The pigeons were then given an additional 20 sessions of training to ensure that there was an adequate association between the response requirement to $\mathrm{C}$ and its respective discriminatory stimuli.

Testing. Each of five test sessions included 36 test trials randomly intermixed among 60 additional training trials. Half of the test trials involved a choice between the two $S+$ stimuli (i.e., $S+{ }_{F R}$ I vs. $\left.S+_{F R 20}\right)$, and the remaining test trials involved a choice between the two $\mathrm{S}-$ stimuli (i.e., $S-{ }_{F R 1}$ vs. $S-{ }_{\text {FR20 }}$ ). Choices on all test trials were randomly reinforced $50 \%$ of the time.

On a third of the test trials involving each test pair, no initiating stimulus preceded the test pair. On the remaining two thirds of the test trials, C was presented at the start of the trial, and on half of those trials, a single peck was required to terminate $\mathrm{C}$ and present the test pair, whereas on the remaining trials 20 pecks were required. Trials involving the initiating responses experienced during training were included to determine whether that response requirement had a direct effect on choice. That is, the pigeons may have learned that following a single peck they should choose $S+{ }_{F R 1}$ and following 20 pecks they should choose $S+{ }_{\text {FR20 }}$. Test trials that did not include an initiating response were included to determine whether any preference would be found without the context provided by the initiating response. Thus, there were six trial types used in testing: trials involving the two $\mathrm{S}+$ stimuli and the two $\mathrm{S}-$ stimuli crossed with each of three initiating conditions (FR1, FR20, and nothing). The test trials were randomly ordered, and the two test stimuli were counterbalanced with regard to the side key on which they appeared. 


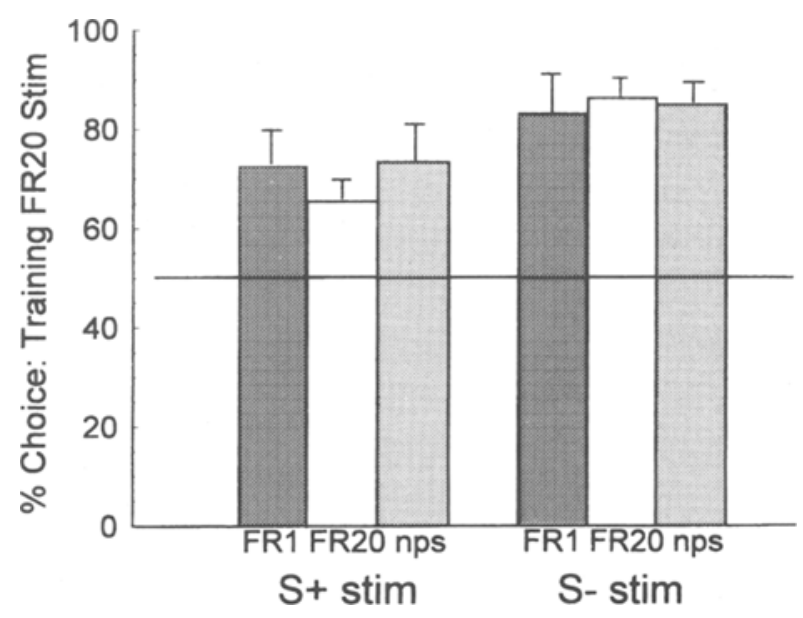

Figure 3. Mean percentage choice of the stimulus ( $S+$ or $S-$ ) that followed the FR20 schedule in training over the stimulus that followed the FR1 schedule in training, when presentation of the test stimuli required 1 peck or 20 pecks, or when there was no prior stimulus (nps, the trial began with the onset of the test stimuli). Error bars indicate the standard error of the mean for each condition.

\section{RESULTS}

\section{Training}

The pigeons acquired the two simple-simultaneous hue discriminations $\left(\mathrm{S}+{ }_{F R 1} \mathrm{~S}-{ }_{F R 1}\right.$ and $\left.\mathrm{S}+_{\mathrm{FR} 20} \mathrm{~S}-{ }_{\mathrm{FR} 20}\right)$ in an average of 2.0 sessions (not including the criterion session). The mean percentage correct for each discrimination during acquisition (not including the criterion session) was $79.1 \%$ correct for the FR 1 discrimination and $85.2 \%$ correct for the FR20 discrimination. However, a dependent $t$ test performed on the percentage correct scores indicated that the difference in acquisition for the two discriminations was not significant $[t(7)=1.19]$. The extensive overtraining ( 20 sessions) ensured that the overall percentages correct on the $\mathrm{S}{ }_{\mathrm{FRI}} \mathrm{S}-{ }_{\mathrm{FRI}}$ discrimination $\left(97.8 \%\right.$ correct) and the $\mathrm{S}+_{F R 20} \mathrm{~S}-{ }_{F R 20}$ discrimination $(98.2 \%$ correct) were quite high and were not significantly different when they were subjected to a dependent $t$ test $(t<1)$.

\section{Testing}

On $\mathrm{S}+_{\mathrm{FR} 1}$ versus $\mathrm{S}+_{\mathrm{FR} 20}$ test trials the pigeons chose the $S+{ }_{F R 20}$ on $69.25 \%$ of the trials. A $t$ test performed on these preference scores indicated that the difference was significantly different from chance $[t(7)=4.07, p<.01]$. On $S-{ }_{F R 1}$ versus $S-_{F R 20}$ test trials, the pigeons chose $\mathrm{S}-{ }_{\mathrm{FR} 20}$ on $84.37 \%$ of the trials. Once again, a $t$ test indicated that the difference was significantly different from chance $[t(7)=6.93, p<.01]$. Finally, a $t$ test performed on the two preference scores, $\mathrm{S}{ }_{{ }_{F R 20}}$ preference versus $S-{ }_{F R 20}$ preference, indicated that the preference for $S-_{F R 20}$ over $S-{ }_{F R 1}$ was not significantly greater than the preference for $\mathrm{S}_{\mathrm{FR} 20}$ over $\mathrm{S}+_{\mathrm{FR} 1}[t(7)=2.00$, $p>.05]$.
An examination of the test trials according to which initiating event preceded the presentation of the test pair indicated that for neither the $\mathrm{S}+$ preference nor the $\mathrm{S}-$ preference did the initiating event (FR1, FR20, or no initiating event) have a significant effect (both $F_{\mathrm{s}}<1$ ). In fact, preference for $\mathrm{S}_{\mathrm{FR} 20}$ was slightly lower $(65.38 \%)$ when the test trial was initiated by an FR20 than when it was initiated by an FR1 (72.62\%) or when there was no initiating stimulus $(73.25 \%)$, and the preference for $\mathrm{S}-{ }_{\mathrm{FR} 20}$ was virtually the same for test trials that were ipitiated by FR2 0 or FR 1, or that had no initiating stimulus $(86.25 \%, 83.12 \%$, and $85.00 \%$, respectively). The data from the experiment are presented in Figure 3.

Finally, the training procedure we used allowed us to ask whether the response rate to the two $\mathrm{S}+$ stimuli in training differed according to which initiating event preceded it. Because each chosen stimulus remained present for $6 \mathrm{sec}$, independent of further responding, we could determine the response rates following each of the choice responses. When we examined the response rates to the $\mathrm{S}+$ stimuli over the last five sessions of training, the mean proportion of the responses to the $\mathrm{S}{ }_{\mathrm{FR} 20}$ divided by total responses to the two $\mathrm{S}+$ stimuli was $\mathbf{4 8 4}$. Thus, there was no indication from the relative response rates in training of the stimulus preference that we had found on test trials.

\section{DISCUSSION}

When, in training, a single peck to an initiating stimulus results in the presentation of one simple-simultaneous discrimination and 20 pecks to the initiating stimulus result in a different simple-simultaneous discrimination, pigeons prefer both the $\mathrm{S}+$ and the $\mathrm{S}-$ that in training followed the 20 pecks over the $S+$ and $S-$ that followed the single peck.

These results are inconsistent with traditional theories of learning, which attribute choice behavior to consequents rather than antecedents (Hull, 1943; Skinner, 1938), because in the present experiment the choice-stimulus consequents were equated for magnitude and delay of reinforcement. The present results are also inconsistent with contiguity-based theories of learning that posit backward associative learning, because those theories predict that the association or context should favor the $\mathrm{S}{ }_{F R 1}-$ the stimulus associated with the least amount of effort. Finally, our results are also inconsistent with contextual (or occasion-setting) effects of the antecedent events (see, e.g., Ross \& Holland, 1981) because preference on test trials was independent of the FR on that trial.

The present results appear to support a relational theory of learning based on the subjective value of the discriminative stimulus relative to the state of the organism immediately prior to the presentation of the stimulus. According to this theory, it is the shift in value (rather than the absolute value) that occurs from the end of the initiating stimulus (which is proposed to be relatively negative on FR20 trials as compared with FR1 trials) to the positive value associated with the onset of the discrimi- 
native stimulus. Although it has generally been assumed that the value of a reinforcer depends primarily on the value of motivational variables such as hunger (level of deprivation) and effort (amount of work), there also is evidence that the value of a reinforcer may depend on the value of the reinforcer expected (incentive contrast; Mellgren, 1972) and on the relative effort required to obtain it (behavioral contrast; Bloomfield, 1969; Halliday \& Boakes, 1972). The results of the present experiment identify another relational factor, the state of the organism immediately prior to presentation of the discriminative stimulus.

Although the present results may be related to other contrast effects (e.g., behavioral contrast), it appears that they have some unique properties of their own. For example, there is evidence that behavioral contrast may be attributable to the pigeons' anticipation of the leaner schedule (Williams, 1981; Williams \& Wixted, 1986), whereas, in the present research, the contrast effect was found in the "component" that followed the poorer schedule (i.e., the schedule that required the greater number of pecks or greater effort).

The present results appear to be most closely related to the between-trial contrast effect known as local contrast (i.e., changes in response rate that occur immediately following the stimulus change that signals a change in schedule; Terrace, 1966). But research has shown that local contrast effects are strongest early in training and that they tend to disappear with extended training. Furthermore, if local contrast were responsible for the contrast effects found in the present experiment, one would have expected that the response rates to the $\mathrm{S}+_{F R 20}$ (during the $6 \mathrm{sec}$ following the first response) would have been higher than those to the $\mathrm{S}{ }_{\mathrm{FR} 1}$, but this was not the case.

As an alternative to a contrast-like effect, preference for the discriminative stimuli that follow greater effort may be related to the arousal-inducing effect of the high FR requirement. A higher level of arousal induced by the FR20 might facilitate the association between the discriminative stimuli and the reinforcer that follows (Eysenck, 1976). But if this were the case, again, one would have expected a higher rate of pecking to the $\mathrm{S}+{ }_{F R 20}$ than to the $\mathrm{S}_{\mathrm{FR} 1}$, and also faster acquisition of the $\mathrm{S}{ }_{\mathrm{FR} 20} \mathrm{~S}-{ }_{\mathrm{FR} 20}$ discrimination than the $\mathrm{S}+_{\mathrm{FR} 1} \mathrm{~S}-{ }_{\mathrm{FRI}}$ discrimination, but neither of these occurred.

Earlier we noted that if backward associative learning occurred in the present experiment, it should result in a preference for $\mathrm{S}+_{\mathrm{FR} 1}$ and $\mathrm{S}-{ }_{\mathrm{FR} 1}$, but it is also possible that the backward pairing of greater effort with a conditioned stimulus could result in conditioned inhibition (Rescorla, 1969). Rescorla has argued that in Pavlovian conditioning, when an unconditioned stimulus (US) precedes the conditioned stimulus (CS), the CS can become a predictor of the absence of the US (i.e., it predicts the intertrial interval). In the present experiment, the conditioned inhibition of an avoidance response (with the FR20 playing the role of the US) and a preference for the CS, or, in this case, the $\mathrm{S}_{{ }_{\mathrm{FR} 20}}$, might result. However, the notion that there is a negative CS-US contingency is based on the premise that the CS actually differentially signals the relative absence of the US. In typical Pavlovian conditioning procedures, that may be the case, because the CS predicts a period of absence of the US; however, in the present experiment, not only were all CSs (S + stimuli) followed by reinforcement but, because of the random presentation of trials, the $\mathrm{S}+_{\mathrm{FR} 20}$ and the $\mathrm{S}+_{\mathrm{FR} 1}$ equally signaled the absence of the next FR20. Thus, a conditioned inhibitory account of the present results would not be easily justified.

The results of the present experiment indicate not only that pigeons prefer the $\mathrm{S}+$ that follows the FR20 schedule over the $\mathrm{S}+$ that follows the FR1 schedule but also that they prefer the $\mathrm{S}-$ that follows the FR20 schedule over the S- that follows the FR1 schedule. Given the $S+{ }_{F R 20}$ preference, the preference for the $S-{ }_{\text {FR20 }}$ can be accounted for by the process of "value transfer" (Zentall \& Sherburne, 1994). Zentall and Sherburne showed that in a simultaneous discrimination task some of the value of an $\mathrm{S}+$ can transfer to its $\mathrm{S}-$, and the greater the value of the $\mathrm{S}+$, the more value there is to transfer to the $\mathrm{S}-$. Specifically, following training on two simultaneous discriminations, $\mathrm{A}+\mathrm{B}-$ and $\mathrm{C} \pm \mathrm{D}-$ (in which responses to $\mathrm{A}$ were always reinforced, responses to $C$ were reinforced on half of the trials, and responses to $B$ and $D$ were not reinforced), on test trials, pigeons preferred B over $D$. In the present experiment, although both $\mathrm{S}+$ stimuli were followed equally by reinforcement, the preference found for the $\mathrm{S}+{ }_{\mathrm{FR} 20}$ suggests that it had more value than the $\mathrm{S}{ }_{\mathrm{FR}}$. And if the $S+_{F R 20}$ had more value than the $S+{ }_{F R 1}$, it should also have had more value to transfer to its corresponding $\mathrm{S}-$.

Grace and Savastano (1997) have proposed that responding to a stimulus may not accurately reflect the value associated with that stimulus. Although this hypothesis was proposed to account for stimulus preference in a freeoperant concurrent discrimination (Belke, 1992), it may apply to the results of the present experiment as well. Belke trained pigeons on two concurrent discriminations involving variable interval (VI) schedules of reinforcement (reinforcement is provided for the first response that occurs after a variable interval): A (VI $20 \mathrm{sec}$ ) versus $B$ (VI $40 \mathrm{sec}$ ), and C (VI $40 \mathrm{sec}$ ) versus D (VI $80 \mathrm{sec}$ ). When the pigeons were tested with a choice between two identical schedules that were from two different contexts in training, B (VI $40 \mathrm{sec}$ ) versus C (VI $40 \mathrm{sec}$ ), C was preferred.

Grace and Savastano (1997) argued that although C elicited more responding than $\mathrm{B}, \mathrm{C}$ may not have been more valued than B (see also Zentall, Weaver, \& Sherburne, 1996). To test this hypothesis, Grace and Savastano separated the reinforcing value of the stimuli from their eliciting strength by using a concurrent-chains procedure. On some trials, one initial link provided the pigeons with access to A (VI $10 \mathrm{sec}$ ) and the other initial link with access to B (VI $20 \mathrm{sec}$ ), and on other trials, one initial link provided access to C (VI $20 \mathrm{sec}$ ) and the other initial link with access to D (VI $40 \mathrm{sec}$ ). Although the initial link to $\mathrm{C}$ was pecked more than the initial link to $\mathrm{B}$, 
when, on test trials, the pigeons were given a choice between $B$ and $C$, they showed indifference. Thus, Grace and Savastano concluded that $C$ was not valued more than $B$; rather, the birds had learned in training to choose the link that led to $\mathrm{C}$ (rather than to D) but not to choose the link that led to $B$ (rather than to A).

In the present experiment, it is possible that the pigeons chose $\mathrm{S}{ }_{\mathrm{FR} 20}$ over $\mathrm{S}{ }_{\mathrm{FR} 1}$ because it elicited more responding rather than because they valued it more. Had their preference for the $S+{ }_{F R 20}$ resulted from increased elicited responding rather than increased value, however, the pigeons should have pecked the $\mathrm{S}+_{\mathrm{FR} 20}$ at a higher rate than the $\mathrm{S}+_{\mathrm{FRI}}$ during the $6 \mathrm{sec}$ that followed the first peck. In fact, there was slightly less responding to the $\mathrm{S}^{\mathrm{FR}_{20}}$ stimulus than to the $\mathrm{S}{ }_{\mathrm{FR} 1}$ stimulus during the last five sessions of training. Thus, differences in elicited responding between the stimuli that followed the FR 1 and the FR20 schedules cannot account for the preference data.

A form of contrast similar to that found in the present experiment may be operating in the case of the classic contrafreeloading effect (see, e.g., Carder \& Berkowitz, 1970; Jensen, 1963; Neuringer, 1969). Pigeons trained to peck a lit response key for food will often obtain food in this way even when presented with a dish of free food. Although it is possible that other factors contribute to the contrafreeloading effect (e.g., reduced familiarity with the free food in the context of the operant chamber-Taylor, 1975; or perhaps preference for small portions of food spaced over time), it is also possible that the pigeons value the food obtained following the effort of keypecking more than the "free" food, and if the effort required is relatively small, they may actually obtain a substantial amount of reward by keypecking.

The present results also have implications for related phenomena that have been found in studies of humans. The term "work ethic" has often been used in the human literature to describe a value or a trait that varies among members of a population as an individual difference (e.g., Greenberg, 1977). But it also can be thought of as a typically human characteristic that appears to be in conflict with traditional learning theory (Hull, 1943). Work (effort) is generally viewed as aversive and as behavior to be avoided, especially if less effortful alternatives lead to reward. Other things being equal, less work should be preferred over more work (and in general it is). Yet, it is also the case that work, per se, is often valued in our culture. Furthermore, the value of a reward may depend on the effort that precedes it. For example, students generally value a high grade that they have received in a course not only for its absolute value, but also in proportion to the effort required of them to obtain it. Similarly, when humans put great effort into a task and the rewards are small, they may adjust the value they place on the reward to justify their effort, a phenomenon known as severity of initiation or justification of effort (Aronson \& Mills, 1959; Gerard \& Mathewson, 1966).
Although, in the case of human examples, cultural factors, including social rewards, may be implicated, a more fundamental, nonsocial mechanism may also be involved. In the absence of social factors, it may generally be the case (as in the present experiment) that the contrast between the hedonic state of the individual immediately prior to reward and at the time of reward may be greater following greater effort than following less effort.

Contrast effects of the kind reported in the present paper may be implicated in other social psychological phenomena. For example, in the case of cognitive dissonance (Festinger, 1957), when humans experience a tedious task, their evaluation of the aversiveness of the task is negatively correlated with the size of the reward provided for agreeing to describe the task to others as pleasurable. The explanation that has been given for the cognitive dissonance effect is that the conflict between attitude (the task was tedious) and behavior (they had agreed to describe the task as enjoyable) was more easily resolved when a large reward was given ("I did it for the large reward"), and thus, a more "honest" evaluation of the task was provided. However, one could also view the contrast between effort and reward to be greater in the large-reward condition than in the small-reward condition. Thus, in the context of large reward, the subjective aversiveness of the prior task might be judged as greater than in the context of small reward.

Similarly, contrast effects of the kind reported here may be responsible for the well-known capacity of extrinsic reinforcement to reduce intrinsic motivation (Deci, 1975; but see also Eisenberger \& Cameron, 1996). If rewards are given for activities that may be "intrinsically rewarding" (e.g., puzzle solving by some college students), providing extrinsic rewards for solving puzzles may lead to a subsequent reduction in puzzle-solving behavior when extrinsic rewards are no longer provided. This effect has been interpreted as a shift in self-determination or locus of control (Deci \& Ryan, 1985; Lepper, 1981). But such effects can also be viewed as examples of contrast. In this case, it may be that the contrast between extrinsic reinforcement and its absence is at least partly responsible for the decline in performance (Flora, 1990). However, such contrast effects are likely to be quite different from those responsible for the results of the present experiment, because the removal of extrinsic reinforcement results in a change in actual reward value relative to the reward value expected (i.e., the shift from a combination of both extrinsic and intrinsic reward to intrinsic reward alone). Thus, the effect of extrinsic reinforcement on intrinsic motivation is probably more similar to traditional rewardshift effects of the kind reported by Crespi (1942, i.e., rats run more slowly after they have been shifted from a large to a small magnitude of reward than rats that have always experienced the small magnitude of reward).

Finally, contrast effects may also be involved in a somewhat different phenomenon that Eisenberger (1992) has called learned industriousness. If one is rewarded for 
putting a large amount of effort (rather than a small amount of effort) into a task, it may increase one's general readiness to expend effort in other goal-directed tasks. Eisenberger has attributed this effect to the conditioned reward value of effort-a reasonable explanation for the phenomenon-but a contrast account can also be described.

Depending on the relative effort required in the first and second tasks, two kinds of relative contrast are possible. First, if the target task is relatively effortful, negative contrast between the previous low-effort task and the target task may make persistence on the second task more aversive for the low-effort group (and its absence less aversive for the high-effort group). Second, if the target task requires relatively little effort, positive contrast between the previous high-effort task and the target task may make persistence less aversive for the high-effort group. In either case, contrast provides a reasonable account of these data.

From the previous discussion, it should be clear that contrast effects of the kind reported in the present study may have contributed to a number of experimental findings that have been reported using humans but that traditionally have been explained using more complex cognitive and social accounts. Further examination of these phenomena from the perspective of simpler contrast effects may lead to more parsimonious explanations of what have previously been interpreted to be uniquely human phenomena.

\section{REFERENCES}

ARONSON, E., \& MILLS, J. (1959). The effect of severity of initiation on liking for a group. Journal of Abnormal \& Social Psychology, 59, 177-181.

Balsam, P. D. (1985). The functions of context in learning and performance. In P. D. Balsam \& A. Tomie (Eds.), Context and learning (pp. 1-21). Hillsdale, NJ: Erlbaum.

BELKE, T. W. (1992). Stimulus preference and the transitivity of preference. Animal Learning \& Behavior, 20, 401-406.

BLOOMFIELD, T. M. (1969). Behavioural contrast and the peak shift. In R. M. Gilbert \& N. S. Sutherland (Eds.), Animal discrimination learning (pp. 215-241). London: Academic Press.

CARDER, B., \& Berkowitz, K. (1970). Rats' preference for earned in comparison with free food. Science, 167, 1273-1274.

CRESPI, L. P. (1942). Quantitative variation in incentive and performance in the white rat. American Journal of Psychology, 40, 467-517.

DeCI, E. (1975). Intrinsic motivation. New York: Plenum.

DECI, E., \& RYAN, R. M. (1985). Intrinsic motivation and selfdetermination in human behavior. New York: Plenum.

Eisenderger, R. (1992). Learned industriousness. Psychological Review, 99, 248-267.

EISENBERgER, R., \& CAMERON, J. ( 1996). Detrimental effects of reward. American Psychologist, 51, 1153-1166.

EYSENCK, M. W. (1976). Arousal, learning, and memory. Psychological Bulletin, 83, 389-404.

FEstinger, L. (1957). A theory of cognitive dissonance. Stanford, CA: Stanford University Press.

FLORA, S. R. (1990). Undermining intrinsic interest from the standpoint of a behaviorist. Psychological Record, 40, 323-346.
Gerard, H. B., \& Mathewson, G. C. (1966). The effects of severity of initiation on liking for a group: A replication. Journal of Experimental Social Psychology, 2, 278-287.

Grace, R. C., \& Savastano, H. I. (1997). Transfer tests of stimulus value in concurrent chains. Journal of the Experimental Analysis of Behavior, 68, 93-115.

Greenberg, J. (1977). The Protestant work ethic and reactions to negative performance evaluations on a laboratory task. Journal of $\mathrm{Ap}$ plied Psychology, 62, 682-690.

GUTHRIE, E. R. (1935). The psychology of learning. New York: Harper.

Halliday, M. S., \& BoakEs, R. A. (1972). Discrimination involving response-independent reinforcement: Implications for behavioural contrast. In R. A. Boakes \& M. S. Halliday (Eds.), Inhibition and learning (pp. 73-97). London: Academic Press.

Hull, C. L. (1943). Principles of behavior. New York: Appleton-CenturyCrofts.

JenSEN, G. D. (1963). Preference of bar pressing over "freeloading" as a function of number of rewarded presses. Journal of Experimental Psychology, 65, 451-454.

LaWrence, D. H., \& Festinger, L. (1962). Deterrents and reinforcement: The psychology of insufficient reward. Stanford, CA: Stanford University Press.

LEPPER, M. R. (1981). Intrinsic and extrinsic motivation in children: Detrimental effects of superfluous social controls. In W. A. Collins (Ed.), Aspects of the development of competence: The Minnesota Symposium on Child Psychology (Vol. 14, pp. 155-214). Hillsdale, NJ: Erlbaum.

Mellgren, R. L. (1972). Positive and negative contrast effects using delayed reinforcement. Learning \& Motivation, 3, 185-193.

NEURINGER, A. J. (1969). Animals respond for food in the presence of free food. Science, 166, 399-401.

Rescorla, R. A. (1969). Conditioned inhibition of fear resulting from negative CS-US contingencies. Journal of Comparative \& Physiological Psychology, 67, 504-509.

REYNOLDS, R. S. (1961). Behavioral contrast. Journal of the Experimental Analysis of Behavior, 4, 57-71.

Ross, R. T., \& Holland, P. C. (1981). Conditioning of simultaneous and serial feature-positive discriminations. Animal Learning $\& B e-$ havior, 9, 293-303.

SkINNER, B. F. (1938). The behavior of organisms. New York: AppletonCentury-Crofts.

SPetch, M. L.,Wilkie, D. M., \& Pinel, J. P. J. (1981). Backward conditioning: A reevaluation of the empirical evidence. Psychological Bulletin, 89, 163-175.

TAYLOR, G. T. (1975). Discriminability and the contrafreeloading phenomenon. Journal of Comparative \& Physiological Psychology, 88, 104-109.

Terrace, H. S. (1966). Stimulus control. In W. K. Honig (Ed.), Operant behavior: Areas of research and application. New York: AppletonCentury-Crofts.

Williams, B. A. (1981). The following schedule of reinforcement as a fundamental determinant of steady state contrast in multiple schedules. Journal of the Experimental Analysis of Behavior, 35, 293-310.

Williams, B. A., \& WixTED, J. T. (1986). An equation for behavioral contrast. Journal of the Experimental Analysis of Behavior, 45, 4762.

Zentall, T. R., \& SherbuRne, L. M. (1994). Transfer of value from S+ to $\mathrm{S}-$ in a simultaneous discrimination. Journal of Experimental Psychology: Animal Behavior Processes, 20, 176-183.

Zentall, T. R., Weaver, J. E., \& Sherburne, L. M. (1996). Value transfer in concurrent-schedule discriminations by pigeons. Animal Learning \& Behavior, 24, 401-409.

(Manuscript received May 15, 1998 ; revision accepted for publication January 4, 1999.) 